\title{
Inflammation Does Not Always Kill Hepatocytes During Liver Damage
}

\section{To the Editor:}

We read the article by Horiguchi et al. ${ }^{1}$ with great interest. It is a commonly accepted dogma that inflammation induces necrosis and apoptosis of hepatocytes during liver damage. However, clinicians have found that inflammation does not always correlate with hepatocellular damage in chronic liver disease. How to explain the conflict? By using a well-established model of mice with specific deletion of signal transducer and activator of transcription 3 in myeloid cells $\left(\right.$ STAT $3^{\text {mye-1- }}$ ), Horiguchi and colleagues surprisingly found more inflammatory cells, eg, neutrophils, but less necrosis/apoptosis in the liver of STAT3 ${ }^{\text {mye-l- }}$ mice than in wild-type mice after carbon tetrachloride $\left(\mathrm{CCl}_{4}\right)$ treatment. STAT3 ${ }^{\text {mye-l-}}$ mice had higher hepatic STAT3 activation and became resistant to hepatic oxidative stress after $\mathrm{CCl}_{4}$ injection compared with wild-type mice. In contrast to STAT3 ${ }^{\text {mye- }-}$ mice, hepatocyte-specific STAT3 knockout $\left(\mathrm{STAT}^{\mathrm{Hep}-1-}\right)$ mice had more liver necrosis/apoptosis but less inflammation after $\mathrm{CCl}_{4}$ treatment compared with wild-type mice. An additional deletion of hepatocyte STAT3 in STAT3 ${ }^{\text {mye- }-}$ mice restored $\mathrm{CCl}_{4}$-induced hepatic necrosis but reduced liver inflammation. This study suggests that inflammation associated with a predominance of hepatoprotective cytokines may reduce rather than accelerate hepatocellular damage via activation of hepatocyte STAT3 in $\mathrm{CCl}_{4-}$ induced liver damage. The data elucidate a potential mechanism that inflammation does not always correlate with hepatocellular damage.

Interestingly, the same group had also previously investigated inflammation and hepatocellular damage in the same strain of STAT3 ${ }^{\text {mye-l- }}$ mice treated with concanavalin A (ConA) or ethanol. ${ }^{2,3}$ STAT3 $3^{\text {mye-l- }}$ mice had higher inflammation concomitant with more severe hepatocellular damage compared with wild-type mice after ConA or ethanol treatment. The discrepancy between ConA- and $\mathrm{CCl}_{4}$-induced liver damage in STAT3 ${ }^{\text {mye-1-}}$ mice could be attributable to the different T helper type 1 (Th1) cytokine $($ IFN- $\gamma)$ responses in these two models. In STAT3 ${ }^{\text {mye-l- }}$ mice, ConA treatment elevated serum IFN- $\gamma$ levels to more than $2500 \mathrm{pg} / \mathrm{mL}$, whereas $\mathrm{CCl}_{4}$ treatment only elevated IFN- $\gamma$ levels to $15 \mathrm{pg} / \mathrm{mL}$. Such high levels of IFN- $\gamma$ in the ConA model not only directly induce liver damage but also inhibit the hepatoprotective STAT3 signal in the liver, further promoting liver injury. ${ }^{3}$ In addition, ethanol consumption significantly inhibited STAT3 activation in STAT3 ${ }^{\text {mye-1- }}$ mice. Thus, the protective role of STAT3 is inhibited in both models of ConA and ethanol treatment. These data suggest that the etiology of liver disease plays a critical role in determining the interplay between inflammation and hepatocellular damage.

In general, the ratio between proinflammatory and anti-inflammatory factors controls the inflammatory level during liver damage; however, the fate of hepatocytes is determined by the balance between the survival and detrimental factors present within the damaged liver. For example, compared to wild-type mice, STAT $3^{\text {mye-l- }}$ mice had increased pro-inflammatory cytokines, eg, IL- 6 , IL-1, IFN- $\gamma$, and chemokines in both the liver and serum. ${ }^{1}$ However, proinflammatory factors do not always kill hepatocytes and some of them such as IL-6 protect rather than kill hepatocytes via activation of survival signal STAT3 in hepatocytes. Thus, inflammation is not always a direct killer of hepatocytes.

Besides the dogma that inflammation leads to hepatocyte death, inflammation is also thought as the critical driver for liver fibrogenesis. However, many studies have demonstrated that inflammation does not always correlate with liver fibrosis in patients with chronic liver disease. ${ }^{4}$ On the other hand, it is well recognized that degradation of fibrosis needs inflammation. ${ }^{5}$ Thus, whether inflammation is a friend or a foe is not a simple question.

Here, we have three questions for the authors: First, in patients with acute liver failure, inflammatory cells, especially monocytes and macrophages, are central to systemic inflammatory response syndrome (SIRS), multiple organ dysfunction syndrome (MODS), and compensation anti-inflammatory response syndrome (CARS). ${ }^{6}$ Compared with SIRS patients, patients with MODS have similar levels of proinflammatory cytokines, but higher levels of antiinflammatory cytokines that suppressed the functions of peripheral and hepatic inflammatory cells. Similarly, in STAT $3^{\text {mye }-1-}$ mice, $\mathrm{CCl}_{4}$ treatment resulted in early elevation of proinflammatory cytokines (at 12 hours after treatment), which remained at the same levels or was decreased at later time points (24 hours). In contrast, the levels of the anti-inflammatory cytokine IL-10 were higher at later time ( 24 hours) than earlier time (12 hours) points. The situation looks very similar to the early stage of MODS in patients with acute liver failure. It would be very interesting to further investigate the ratio of proinflammatory and anti-inflammatory cytokines/chemokines in STAT3 ${ }^{\text {mye-l- }}$ mice at 36 hours after $\mathrm{CCl}_{4}$ treatment. Second, the authors investigated the relationship between inflammation and hepatocellular damage in "chronic" liver disease. However, the maximal $\mathrm{CCl}_{4}$ treatment time period in the present study was 72 hours, and most of data were obtained from the mice treated with $\mathrm{CCl}_{4}$ within 24 hours. It would be very interesting to investigate the inflammation and hepatocelluar damage in real "chronic liver disease", eg, mice subjected to 4 weeks of $\mathrm{CCl}_{4}$-treatment. Finally, we are very interested in the relationship between inflammation and fibrosis in these mice treated chronically with $\mathrm{CCl}_{4}$.

Anyway, we appreciate Horiguchi and colleagues for providing such fascinating work for further discussion.

\author{
Honglei Weng, Ph.D. ${ }^{1}$ \\ HAI LI, M.D. ${ }^{2}$ \\ Steven Dooley, Ph.D. ${ }^{1}$ \\ ${ }^{1}$ Medical Clinic II, Faculty of Medicine at Mannheim \\ University of Heidelberg, Mannheim, Germany \\ ${ }^{2}$ Department of Gastroenterology, Renji Hospital \\ Shanghai Jiaotong University, Shanghai, China
}

\section{References}

1. Horiguchi N, Lafdil F, Miller AM, Park O, Wang H, Rajesh M, et al. Dissociation between liver inflammation and hepatocellular damage induced by carbon tetrachloride in myeloid cell-specific signal transducer and activator of transcription 3 gene knockout mice. HePATOLOGY 2010;51:1724-1734.

2. Horiguchi N, Wang L, Mukhopadhyay P, Park O, Jeong WI, Lafdil F, et al. Cell type-dependent pro- and anti-inflammatory role of signal transducer and activator of transcription 3 in alcoholic liver injury. Gastroenterology 2008;134:1148-1158.

3. Lafdil F, Wang H, Park O, Zhang W, Moritoki Y, Yin S, et al. Myeloid STAT3 inhibits T cell-mediated hepatitis by regulating T helper 1 cytokine and interleukin-17 production. Gastroenterology 2009;137: 2125-2135 e2121-2122.

4. Ahmed A, Keeffe EB. Chronic hepatitis C with normal aminotransferase levels. Gastroenterology 2004;126:1409-1415.

5. Wynn TA. Cellular and molecular mechanisms of fibrosis. J Pathol 2008;214:199-210.

6. Antoniades CG, Berry PA, Wendon JA, Vergani D. The importance of immune dysfunction in determining outcome in acute liver failure. J Hepatol 2008;49:845-861.

Copyright $\odot 2011$ by the American Association for the Study of Liver Diseases. View this article online at wileyonlinelibrary.com. DOI 10.1002/hep.24166

Potential conflict of interest: Nothing to report. 


\section{Reply:}

We highly appreciate the comments by Weng and colleagues. Our laboratory has been focusing on the role of inflammation in liver injury, fibrosis, and regeneration by using a model of myeloid cell-specific signal transducer and activator of transcription 3 (STAT3) knockout (STAT3 ${ }^{\text {mye-1-}}$ ) mice. As it was previously reported, STAT3 ${ }^{\text {mye-l- }}$ mice are highly susceptible to endotoxin shock with increased production of inflammatory cytokines. ${ }^{1} \mathrm{We}$ demonstrated that STAT3 ${ }^{\text {mye-1- }}$ mice were resistant to liver damage after carbon tetrachloride $\left(\mathrm{CCl}_{4}\right)$ injection, ${ }^{2}$ but more susceptible to concanavalin A-induced and ethanol-induced liver damage, accompanied by more inflammatory cells in the liver. ${ }^{3,4}$ We believe, as Weng and colleagues summarized, the balance between pro- and anti-inflammatory cytokines determines the fate of hepatocyte survival or death. These results suggest that the etiology of liver injury determines whether inflammatory cells contribute to attenuating or worsening liver damage.

Weng et al. also raised an important point regarding the effect of inflammation on liver fibrogenesis. Although we have not examined $\mathrm{CCl}_{4}$-induced chronic liver injury and fibrosis in STAT3 ${ }^{\text {mye-l- }}$ mice, the effects of inflammation on fibrogenesis in these mice may be complex. Inflammation not only contributes to fibrogenesis, but also plays an important role in the resolution of liver fibrosis. ${ }^{5}$ In our study, STAT3 ${ }^{\text {mye-l- }}$ mice had high levels of liver inflammation associated with higher levels of tumor necrosis factor- $\alpha$, interleukin-1 (IL-1), and IL-6, which are known to promote liver fibrosis, but also higher levels of IL-10 and interferon- $\gamma$, which are known to inhibit liver fibrosis. The balance between these pro- and antifibrogenic cytokines will likely play an important role in determining the progression of liver fibrogenesis in STAT3 $3^{\text {mye-l- }}$ mice after chronic $\mathrm{CCl}_{4}$ treatment.
Norio Horiguchi, M.D., Ph.D. ${ }^{1,2}$

BIN GAO, M.D., PH.D. ${ }^{1}$

${ }^{1}$ Laboratory of Liver Diseases

National Institute on Alcohol Abuse and Alcoholism

National Institutes of Health, Bethesda, MD

${ }^{2}$ Department of Medicine and Molecular Science, Gunma University Graduate School of Medicine, Gunma, Japan

\section{References}

1. Takeda K, Clausen BE, Kaisho T, Tsujimura T, Terada N, Förster I, et al. Enhanced Th1 activity and development of chronic enterocolitis in mice devoid of Stat3 in macrophages and neutrophils. Immunity 1999;10:39-49.

2. Horiguchi N, Lafdil F, Miller AM, Park O, Wang H, Rajesh M, et al. Dissociation between liver inflammation and hepatocellular damage induced by carbon tetrachloride in myeloid cell-specific signal transducer and activator of transcription 3 gene knockout mice. HePATOLOGY 2010;51:1724-1734.

3. Lafdil F, Wang H, Park O, Zhang W, Moritoki Y, Yin S, et al. Myeloid STAT3 inhibits $\mathrm{T}$ cell-mediated hepatitis by regulating $\mathrm{T}$ helper 1 cytokine and interleukin-17 production. Gastroenterology 2009;137:2125-2135.

4. Horiguchi N, Wang L, Mukhopadhyay P, Park O, Jeong WI, Lafdil F, et al. Cell type-dependent pro- and anti-inflammatory role of signal transducer and activator of transcription 3 in alcoholic liver injury. Gastroenterology 2008;134:1148-1158.

5. Duffield JS, Forbes SJ, Constandinou CM, Clay S, Partolina M, Vuthoori $S$, et al. Selective depletion of macrophages reveals distinct, opposing roles during liver injury and repair. J Clin Invest 2005;115:56-65.

Copyright $\odot 2011$ by the American Association for the Study of Liver Diseases. View this article online at wileyonlinelibrary.com.

DOI 10.1002/hep.24383

Potential conflict of interest: Nothing to report.

\section{Screening for Biliary Atresia: Swiss Stool Color Card}

\section{To the Editor:}

With great interest, we read the report by Lien et al. ${ }^{1}$ on their experience with using a stool color card (SCC) for the early identification of babies with biliary atresia. So far, Taiwan is the only country with regular, nationwide screening for this devastating disease. With this screening, the age for Kasai hepatoportoenterostomy has significantly dropped, and this has meant a significant increase in jaundicefree survival with the native liver at the age of 3 years. The same Taiwanese group has shown that the sensitivity and specificity of the SCC for the detection of biliary atresia are $97.1 \%$ and $99.9 \%$, respectively. ${ }^{2}$

Biliary atresia is one of the most progressive fibrogenic liver diseases. The more advanced the liver fibrosis is at the time of the Kasai operation, the worse the chances are for the child to live with his or her own liver; increased age at the time of surgery has a progressive and sustained deleterious effect on the results of the Kasai operation until adolescence. ${ }^{3-5}$

The criteria for a condition to be considered appropriate for newborn screening are as follows: (1) the condition is an important health problem; (2) there is a recognizable latent period or an early symptomatic period during which intervention may be beneficial; (3) there are suitable screening tests or examinations that are acceptable, reliable, easy to apply, and available; and (4) there are accepted treatments that are available and beneficial when they are applied early. ${ }^{6,7}$ The implementation of screening for biliary atresia is thus justified. Moreover, the reported results convincingly demonstrate that in Taiwan, the SCC is a simple, noninvasive, efficient, low-cost, and applicable mass screening method for the early diagnosis and management of biliary atresia.

These considerations led to the design of a Swiss national biliary atresia screening pilot program, which was started in 2009. The Swiss SCC is available in German, French, Italian, and English (Fig. 1). It is explained and handed out to the parents after their child's birth by the attending pediatrician or midwife. An instructive Web site for parents and health care personal has been established (http:// www.basca.ch). The SCC and the baby's stool color are checked during the first visit with the treating physician, usually at the age of 4 weeks. During the current pilot period for the screening, SCC data are immediately transmitted to the coordination center in Geneva, Switzerland, to evaluate the feasibility and acceptance of the screening program: Switzerland obviously has a culture and mentality different from those of Taiwan. If an abnormal stool color is discovered, a further evaluation of the baby is immediately performed. By signing the SCC, the parents give their informed, written consent to the physician to communicate the data to the coordination center.

The current program is open to all interested physicians, and SCCs can be ordered for free via the Web site (http://www.basca. ch). The screening is voluntary, and money is not received by the patient, the participating physician, or the coordination center.

$$
\begin{aligned}
& \text { Barbara E. Wildhaber, M.D. } \\
& \text { Service of Pediatric Surgery } \\
& \text { Children's Hospital of Geneva } \\
& \text { University Hospital of Geneva } \\
& \text { Geneva, Switzerland }
\end{aligned}
$$




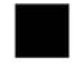

\section{STOOL COLOR CARD}

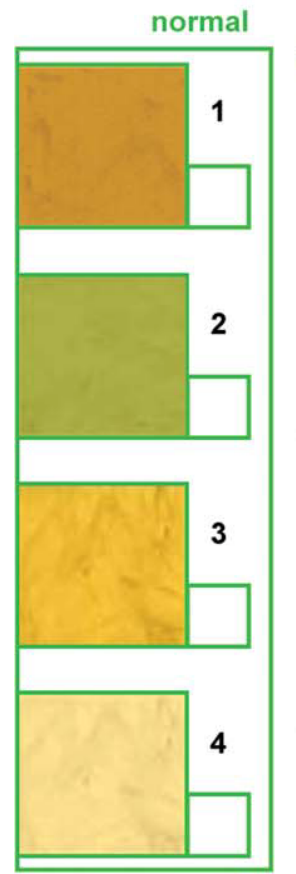

Fig. 1. English version of the Swiss SCC for biliary atresia screening. Published with the permission of the program director.

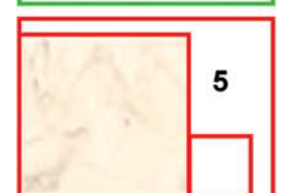

\section{Your baby's stool color}

Dear parents,

Observe your baby's stool color! Some liver diseases manifest with abnormal stool color. If it resembles images $5-7$ (discolored stools), further investigations have to be carried out.

However your baby's stool color is, bring this card with you, when you see your pediatrician for the first time, at the end of the first month of your baby's life.

Observe your baby's stool color during the 1st month of life. If the stool discolors, the patency of the bile ducts which lead the bile from the liver towards the intestine need to checked. The observation of the stool color during the first month of life allows to easily diagnose most obstructions of the bile ducts. These diseases need a treatment as quickly as possible.

If you have questions, don't hesitate to contact your pediatrician. You also find more information on the website www.basca.ch.

This screening with the Stool Color Card was successful in other countries. In Switzerland it is performed within the scope of a pilot study, before it is definitively introduced. The information on the card, and the final diagnosis in case of abnormal stool color, is collected by the coordination centre of the study (BASCA) located at the University of Geneva. This information is made anonymous. Your child's data are absolutely confidential and remain with your pediatrician and with the coordination centre. This screening is voluntary and neither you nor your pediatrician nor the coordination centre receive money. This project was approved by the Ethical Committee of the University Hospitals of Geneva.

By handing out this signed Stool Color Card to your pediatrician you give your consent that its information and an potential final diagnosis are transmitted to the coordination centre (BASCA).

To the pediatrician:

Please register the data after the consultation on www.basca.ch, or fax the card to: BASCA, Fax +41 (0)22 3825085

6 For more information: www. bascach

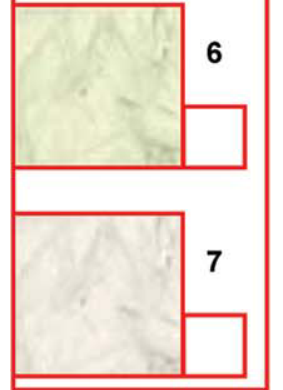

abnormal

Physician's stamp

Protions

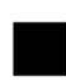

BASCA - Biliary Atresia Screening Association

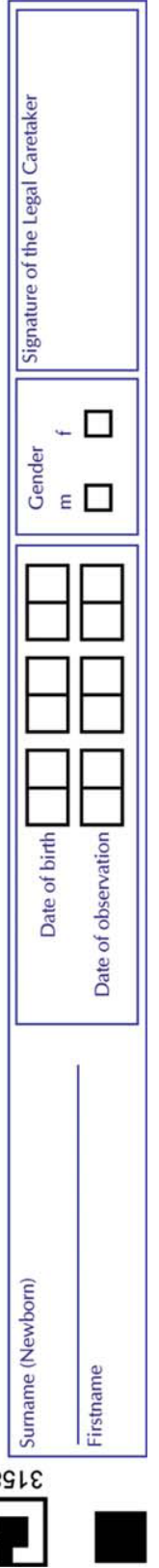

\section{References}

1. Lien TH, Chang MH, Wu JF, Chen HL, Lee HC, Chen AC, et al. Effects of the infant stool color card screening program on 5-year outcome of biliary atresia in Taiwan. Hepatology 2011;53:202-208.

2. Hsiao $\mathrm{CH}$, Chang MH, Chen HL, Lee HC, Wu TC, Lin CC, et al. Universal screening for biliary atresia using an infant stool color card in Taiwan. Hepatology 2008;47:1233-1240.

3. Wildhaber BE, Coran AG, Drongowski RA, Hirschl RB, Geiger JD, Lelli JL, et al. The Kasai portoenterostomy for biliary atresia: a review of a 27-year experience with 81 patients. J Pediatr Surg 2003;38:1480-1485.

4. Wildhaber BE, Majno P, Mayr J, Zachariou Z, Hohlfeld J, Schwoebel M, et al. Biliary atresia: Swiss national study, 1994-2004. J Pediatr Gastroenterol Nutr 2008;46:299-307.

5. Serinet MO, Wildhaber BE, Broué P, Lachaux A, Sarles J, Jacquemin $\mathrm{E}$, et al. Impact of age at Kasai operation on its results in late child- hood and adolescence: a rational basis for biliary atresia screening. Pediatrics 2009;123:1280-1286.

6. Therrell BL Jr. U.S. newborn screening policy dilemmas for the twenty-first century. Mol Genet Metab 2001;74:64-74.

7. Powell JE, Keffler S, Kelly DA, Green A. Population screening for neonatal liver disease: potential for a community-based programme. J Med Screen 2003;10:112-116.

Copyright $(2011$ by the American Association for the Study of Liver Diseases. View this article online at wileyonlinelibrary.com.

DOI 10.1002/hep.24346

This study was supported by the Association Enfance et Maladies Orphelines, the Centre de Recherche Clinique des Hôpitaux Universitaires de Genève, Novartis Pharma, Astellas Pharma, and the Wyeth Foundation.

Potential conflict of interest: Nothing to report. 


\section{Reply:}

We appreciate the comments from Dr. Wildhaber. Biliary atresia (BA) is the most common cause of liver death in children. Through the stool color card screening program, the prognosis of BA can be improved remarkably by early detection and timely surgery. The stool color card screening program is indeed a noninvasive, low-cost, and simple screening tool that is suitable for mass screening. ${ }^{1,2}$ We are pleased to learn of the launch of the Swiss national biliary atresia screening program. This is a positive support to our stool card screening program in Taiwan. We hope to see more countries begin the implementation of the universal stool color card screening program for BA in children. As we understand, experts from quite a number of countries, including Canada, Malaysia, Australia, and the Philippines, among others, have started or are planning a pilot study for the stool color card screening program for BA.

Our stool color card is available in other languages for new immigrants to Taiwan, including versions in English, Vietnamese, Thai, Indonesian, and Khmer (Kampuchea). In addition, the stool color card has been integrated into a child health booklet. Educational lectures were given to health and medical personnel, and periodically to day care workers.. Posters were also put up in local clinics and hospitals to propagate the related knowledge. Many previous studies had shown the importance of earlier detection for $\mathrm{BA}^{3-5}$ Our experience provides evidence that the stool color card is a good screening tool for BA. Continuous efforts to actively promote early detection is mandatory to improve the long-term outcome of BA. We believe that the stool color card is a blessing for children's health.
Tien-Hau Lien, M.D.

Mei-Hwei Chang, M.D.

Department of Pediatrics, National Taiwan University Hospital Taipei, Taiwan

\section{References}

1. Hsiao CH, Chang MH, Chen HL, Lee HC, Wu TC, Lin CC, et al.; Taiwan Infant Stool Color Card Study Group. Universal screening for biliary atresia using an infant stool color card in Taiwan. Hepatology 2008;47:1233-1240.

2. Lien TH, Chang MH, Wu JF, Chen HL, Lee HC, Chen AC, et al.; Taiwan Infant Stool Color Card Study Group. Effects of the infant stool color card screening program on 5-year outcome of biliary atresia in Taiwan. Hepatology 2011;53:202-208.

3. Wildhaber BE, Majno P, Mayr J, Zachariou Z, Hohlfeld J, Schwoebel M, et al. Biliary atresia: Swiss national study, 1994-2004. J Pediatr Gastroenterol Nutr 2008;46:299-307.

4. Shneider BL, Brown MB, Haber B, Whitington PF, Schwarz K, Squires $\mathrm{R}$, et al.; Biliary Atresia Research Consortium. A multicenter study of the outcome of biliary atresia in the United States, 1997 to 2000. J Pediatr 2006;148:467-474.

5. Chardot C, Carton M, Spire-Bendelac N, Le Pommelet C, Golmard JL, Auvert B. Prognosis of biliary atresia in the era of liver transplantation: French national study from 1986 to 1996. HePATOLOGY 1999;30:606-611.

Copyright $(2011$ by the American Association for the Study of Liver Diseases. View this article online at wileyonlinelibrary.com.

DOI 10.1002/hep.24382

Potential conflict of interest: Nothing to report.

\section{Misuse of Scoring Systems}

\section{To the Editor:}

We wish to comment on the article entitled "Pathologic Criteria for Nonalcoholic Steatohepatitis: Interprotocol Agreement and Ability to Predict Liver-Related Mortality" by Younossi et al., ${ }^{1}$ which was recently published in Hepatology. The stated goals of the study were 2-fold: (1) to compare the results of biopsy interpretations made according to three previously published histological scoring systems $\mathrm{s}^{2-4}$ and a previously unpublished system ${ }^{1}$ for the histopathological diagnosis of nonalcoholic steatohepatitis (NASH) and (2) to compare the use of these systems for the prediction of long-term mortality. The study cohort consisted of patients with biopsy-proven nonalcoholic fatty liver disease (NAFLD) who had at least 5 years of follow-up.

Details of the utilization of the previously described histological scoring systems provide insight into our concerns. Matteoni et al. ${ }^{2}$ described a system for the categorization of the spectrum of diseases in NAFLD and classified cases into four types: (1) steatosis, (2) steatosis plus inflammation, (3) steatosis plus ballooning, and (4) steatosis plus Mallory-Denk bodies or fibrosis. This classification system was not used to identify the presence or absence of NASH in the original study according to Younossi et al. The degree of inflammation and its location (portal or lobular) were not specified in the system, nor was the degree of fibrosis or its zonality (perisinusoidal or portal). On the other hand, the Brunt proposal ${ }^{3}$ for grading and staging NASH was just that: a proposal, published in the same year as the Matteoni classification system, that followed the same paradigm used in chronic hepatitis for separating grading (activity) and staging (fibrosis). This proposal was, however, not intended for estab- lishing a diagnosis of NASH. This system was applied to liver biopsy samples only after NASH had been diagnosed and not to cases with steatosis only or steatosis and inflammation. Thus, the use of "fat plus lobular inflammation" for a "Brunt" diagnosis of "NASH" by Younossi et al. is the result of a misunderstanding, and this misapplication of the proposal has led to their conclusion that the system results in the overdiagnosis of NASH.

The National Institutes of Health-sponsored NASH Clinical Research Network system, which is called the Kleiner scoring system, ${ }^{4}$ also separates the activity [nonalcoholic fatty liver disease activity score (NAS)] and the stage (fibrosis). The NAS comprises steatosis, inflammation and ballooning only, and no fibrosis, as implied by Younossi et al. ${ }^{1}$ Importantly, the NAS scoring system was not intended to be used as a surrogate for a diagnostic determination of NASH versus NAFLD without NASH. Although, as noted by Younossi et al., other authors have used the NAS as a surrogate for establishing a diagnosis of $\mathrm{NASH}$, neither the NASH Clinical Research Network nor we as the participating pathologists have ever supported the use of the system for diagnosis in writing or presentations. Furthermore, as we have recently demonstrated, although higher NAS scores correlate with a diagnosis of NASH statistically, they have separate and distinct clinical meanings, and the NAS cannot replace the histological diagnosis. ${ }^{5}$

Unfortunately, Younossi et al. ${ }^{1}$ also assessed both the Brunt and Kleiner scoring systems for another purpose for which they were not designed: the prediction of liver-related mortality. Interestingly, they tested these systems against the Matteoni system, which was developed specifically for this purpose. Several statistical analyses 
were performed and led to a final conclusion confirming what has been shown in many studies of NASH over the past decades: hepatic fibrosis is a predictor of long-term morbidity/mortality.

In conclusion, the comparison of histological grading and staging systems and the validation of their elements against clinical outcomes are important goals in clinical investigation. Of utmost importance in these types of studies, however, is careful attention to the details of the methods that are used. The "Brunt" and "NAS" systems, as applied in this article, ${ }^{1}$ have not been appropriately used in this context, and we emphasize this to the editor and the readers of this article to dispel any potential misunderstandings about the usefulness of these grading systems when they are applied in the appropriate way.

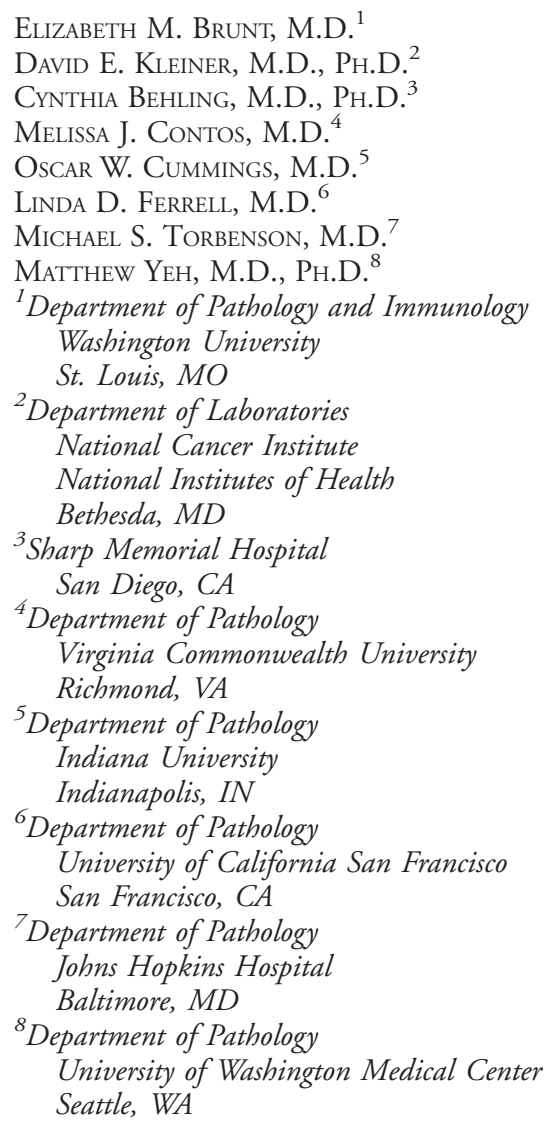

\section{References}

1. Younossi Z, Stepanova M, Rafiq N, Makhlouf H, Younoszai Z, Agrawal R, et al. Pathologic criteria for nonalcoholic steatohepatitis: interprotocol agreement and ability to predict liver-related mortality. Hepatology 2011.

2. Matteoni CA, Younossi ZM, Gramlich T, Boparai N, Liu YC, McCullough AJ. Nonalcoholic fatty liver disease: a spectrum of clinical and pathological severity. Gastroenterology 1999;116:1413-1419.

3. Brunt EM, Janney CG, Di Bisceglie AM, Neuschwander-Tetri BA, Bacon BR. Nonalcoholic steatohepatitis: a proposal for grading and staging the histological lesions. Am J Gastroenterol 1999;94: 2467-2474.

4. Kleiner DE, Brunt EM, Van Natta M, Behling C, Contos MJ, Cummings OW, et al. Design and validation of a histological scoring system for nonalcoholic fatty liver disease. Hepatology 2005;41:1313-1321.

5. Brunt EM, Kleiner DE, Wilson L, Belt P, Neuschwander-Tetri BA, for the NASH Clinical Research Network. The NAS and the histopatholoic diagnosis of NASH: distinct clinicopathologic meanings. HEPATOLOGY 2011;53:810-820.
Copyright (C) 2011 by the American Association for the Study of Liver Diseases. View this article online at wileyonlinelibrary.com.

DOI 10.1002/hep.24347

Potential conflict of interest: Nothing to report.

Reply:

We thank Dr. Brunt and colleagues for their interest in our article. We agree that validation against clinical outcome is important for any grading and staging system. Our study was designed to examine the relationship of histopathologic features to liver-related mortality in nonalcoholic fatty liver disease (NAFLD), and so among other assessments, we included two widely used scoring systems. ${ }^{1,2}$

Regarding NAFLD activity score (NAS), we agree that the original description and subsequent confirmation discouraged its use for diagnosis of nonalcoholic steatohepatitis (NASH), ${ }^{2,3}$ and as noted in our article, our results confirmed this.

Regarding the score presented by Brunt et al., we strictly adhered to the definitions in its original description. ${ }^{1}$ It is true that the score was intended for grading biopsies diagnosed with NASH. However, the article's description of mild NASH is quite clear and precise: "Steatosis (predominantly macrovesicular) involving up to $66 \%$ of biopsy; may see occasional ballooned zone 3 hepatocytes; scattered rare intra-acinar polymorphonucleocytes and/or intra-acinar lymphocytes; no or mild portal chronic inflammation." Steatosis and mild lobular inflammation are mandatory parts of this definition of mild NASH, but ballooning is optional. Elsewhere, the description of mild NASH includes "Ballooning and disarray are minimally present, if at all." It also noted "these biopsies meet the minimum criteria for steatohepatitis." By contrast, the description of moderate NASH says "Ballooning and disarray are always present." Therefore, this means that any biopsy with steatosis and mild lobular inflammation can be interpreted as mild NASH according to the original criteria described in Brunt et al.

It is important to remember that regardless of intended use, all pathologic grading and staging systems are based on the premise that what looks bad to the pathologist will be worse for patients. If the goal of a clinical trial is to improve histologic characteristics, it is with the presumption that histologic improvement will decrease an adverse long-term outcome. A true evidence-based test of that hypothesis requires a study with long-term outcome as the endpoint. If under the rubric of NASH we exclude Brunt's grade 1 or mild NASH, its performance in predicting liver-related mortality improves significantly. In contrast, NAS does not directly translate to a diagnosis of NASH and is more useful for assessing shortterm histologic changes in clinical trials, as was its intent.

Finally, we must disagree with the statement that "many" studies have shown that hepatic fibrosis is a predictor of long-term morbidity and/or mortality in NASH. We know of only three other nonalcoholic fatty liver disease studies (combined patients $=302$ ) that assessed histology and long-term outcome. It seems likely that further advances in histologic predictors of natural history will require a much larger number of patients with long-term follow-up.

\author{
Zachary Goodman, M.D., Ph.D. ${ }^{1}$ \\ Hala Makhlouf, M.D., Ph.D. ${ }^{2}$ \\ Zobair YounOssi, M.D., M.P.H. ${ }^{1}$ \\ ${ }^{1}$ Center for Liver Diseases, Inova Fairfax Hospital, Falls Church, VA \\ ${ }^{2}$ Armed Forces Institute of Pathology, Washington, DC
}

\section{References}

1. Brunt EM, Janney CG, Di Bisceglie AM, Neuschwander-Tetri BA, Bacon BR. Nonalcoholic steatohepatitis: a proposal for grading and 
staging the histological lesions. Am J Gastroenterol 1999;94: 2467-2474.

2. Kleiner DE, Brunt EM, Van Natta M, Behling C, Contos MJ, Cummings OW, et al.; Nonalcoholic Steatohepatitis Clinical Research Network. Design and validation of a histological scoring system for nonalcoholic fatty liver disease. Hepatology 2005;41:1313-1321.

3. Brunt E, Kleiner D, Wilson L, Belt P, Neuschwander-Tetri BA; NASH Clinical Research Network. The NAS and the histopathologic diagnosis in nonalcoholic steatohepatitis: Distinct clinicopathologic meanings. Hepatology 2011;53:810-820.

Copyright $\odot 2011$ by the American Association for the Study of Liver Diseases. View this article online at wileyonlinelibrary.com.

DOI 10.1002/hep. 24380

Potential conflict of interest: Nothing to report.

\section{Efforts at Making the Diagnosis of Acute-Onset Autoimmune Hepatitis}

\section{To the Editor:}

We read with great interest the article by Stravitz et al., ${ }^{1}$ who report that patients with indeterminate acute liver failure (ALF) often have features of autoimmune hepatitis (AIH) according to histological, serological, and clinical analyses. Fifty-eight percent of their patients with indeterminate ALF were diagnosed with probable AIH-ALF on the basis of pathological features, and they had higher serum globulin levels and higher levels of anti-nuclear antibodies, anti-smooth muscle antibodies, or both in comparison with patients without histological findings suggestive of probable AIH-ALF.

As hepatologists struggling against intractable liver diseases in Japan, we applaud their efforts at making the diagnosis of acuteonset AIH.

In past Japanese surveys of ALF, a specific etiology could not be identified in $30 \%$ to $40 \%$ of adult patients. ${ }^{2}$ Since the establishment of the criteria of the International Autoimmune Hepatitis Group $^{3}$ and the recognition of acute-onset AIH, patients with autoimmune ALF have begun to be diagnosed. ${ }^{4}$ However, in the early stages of their illness, they often demonstrate a histological pattern atypical for AIH that consists of centrilobular necrosis with or without portal changes. ${ }^{5-7}$

Recently, we have also reported that AIH is not a rare cause of ALF in our unit, and the number of patients with unknown causes could decrease according to the precise diagnosis of $\mathrm{AIH}$, which is based on a combination of the aforementioned pathological features and the original revised criteria. ${ }^{8}$ In our unit, AIH has been involved in $29 \%$ of ALF cases, and unknown causes have been involved in $12 \%$; this means that in comparison with the results of a national survey, approximately half of our patients with unknown causes have been diagnosed with AIH-ALF.

In our recent studies, ${ }^{7-10}$ the severity of acute-onset $\mathrm{AIH}$ was not high at its onset in most patients, but some of them advanced to severe diseases without a precise diagnosis or treatment. For an early diagnosis, it is most important to exclude other causes systematically, to remember acute-onset $\mathrm{AIH}$ in the differential diagnosis, and then to apply the scoring system; comprehensive evaluations of clinical, biochemical, radiological, and histological features are necessary. In particular, a precise pathological evaluation plays an important role in the differential diagnosis, as the authors describe. However, this is complicated by the fact that there is still no gold standard for making the diagnosis of acuteonset $\mathrm{AIH}$, as the authors repeatedly note.

We believe that one of the pathological characteristics of acuteonset $\mathrm{AIH}$ is its histological heterogeneity, especially in severe and fulminant AIH. Histological heterogeneity leads to radiological heterogeneity. Unenhanced computed tomography often shows hypoattenuated and hyperattenuated areas, with the former reflecting massive hepatic necrosis and the latter reflecting regenerative islands. Ultrasound shows similar heterogeneity. Histological heterogeneity also leads to clinical heterogeneity. The time from onset to admission to our unit did not differ with the clinical severity (nonsevere, severe, or fulminant), and the time from onset to histological examination did not differ with the histological features (chronic hepatitis, severe acute hepatitis, or massive/submassive necrosis; Fig. 1).
A

days

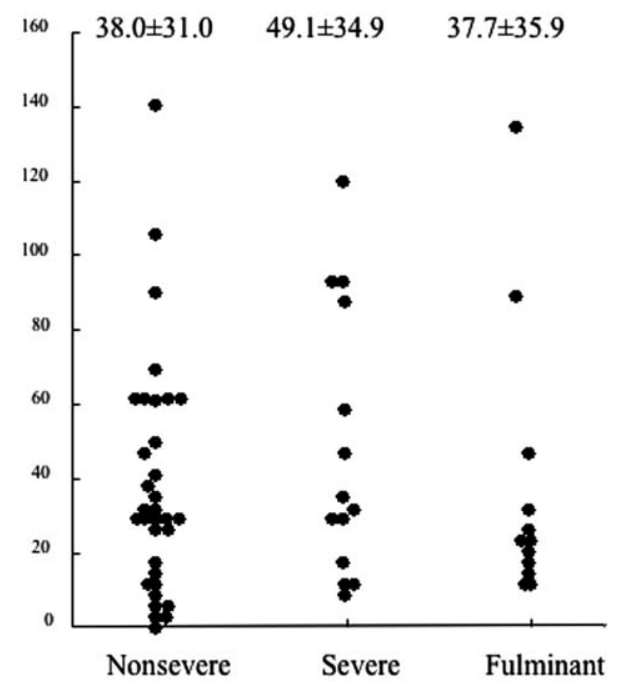

B

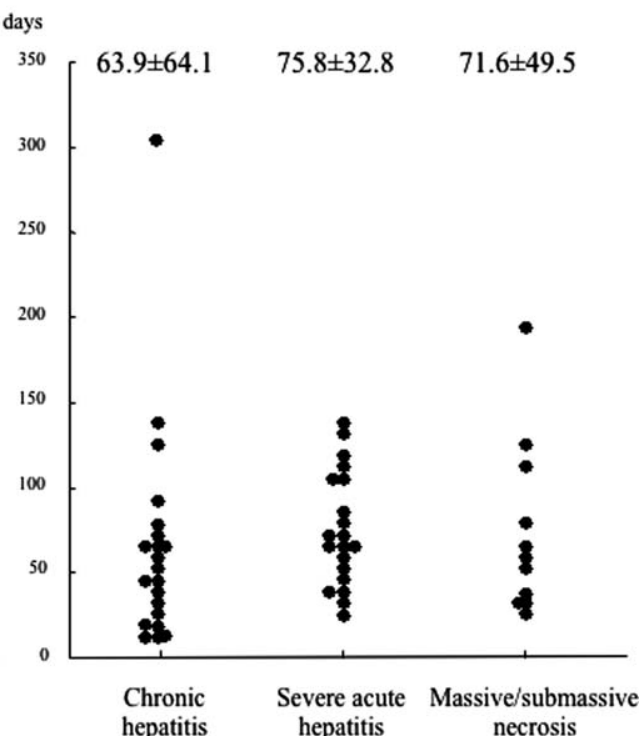

Fig. 1. Associations between (A) the clinical severity and the time from onset to admission and (B) the histological features and the time from onset to histological examination. 
Characteristic morphological patterns of liver necrosis and regeneration should exist in patients with acute-onset $\mathrm{AIH}$, and a better understanding of these patterns would be helpful in making the diagnosis.

KeIICHI FujIWARA, M.D.

SHin Yasui, M.D.

OSAMu YoKosuKa, M.D.

Department of Medicine and Clinical Oncology

Graduate School of Medicine, Chiba University, Chiba, Japan

\section{References}

1. Stravitz RT, Lefkowitch JH, Fontana RJ, Gershwin ME, Leung PS, Sterling RK, et al., for Acute Liver Failure Study Group. Autoimmune acute liver failure: proposed clinical and histological criteria. HepatoLOGY 2011;53:517-526.

2. Fujiwara K, Mochida S, Matsui A, Nakayama N, Nagoshi S, Toda G, for Intractable Liver Diseases Study Group of Japan. Fulminant hepatitis and late onset hepatic failure in Japan. Hepatol Res 2008;38:646-657.

3. Alvarez F, Berg PA, Bianchi FB, Bianchi L, Burroughs AK, Cancado EL, et al. International Autoimmune Hepatitis Group report: review of criteria for diagnosis of autoimmune hepatitis. J Hepatol 1999;31:929-938.

4. Kessler WR, Cummings OW, Eckert G, Chalasani N, Lumeng L, Kwo PY. Fulminant hepatic failure as the initial presentation of acute autoimmune hepatitis. Clin Gastroenterol Hepatol 2004;2: 625-631.

5. Misdraji J, Thiim M, Graeme-Cook FM. Autoimmune hepatitis with centrilobular necrosis. Am J Surg Pathol 2004;28:471-478.

6. Abe M, Onji M, Kawai-Ninomiya K, Michitaka K, Matsuura B, Hiasa $\mathrm{Y}$, et al. Clinicopathologic features of the severe form of acute type 1 autoimmune hepatitis. Clin Gastroenterol Hepatol 2007;5:255-258.

7. Fujiwara K, Fukuda Y, Yokosuka O. Precise histological evaluation of liver biopsy specimen is indispensable for diagnosis and treatment of acute-onset autoimmune hepatitis. J Gastroenterol 2008;43:951-958.

8. Fujiwara K, Yasui S, Tawada A, Okitsu K, Yonemitsu Y, Chiba T, et al. Autoimmune fulminant liver failure in adults: experience in a Japanese center. Hepatol Res 2011;41:133-141.

9. Fujiwara K, Nakano M, Yasui S, Okitsu K, Yonemitsu Y, Yokosuka O. Advanced histology and impaired liver regeneration are associated with disease severity in acute onset autoimmune hepatitis. Histopathology; doi:10.1111/j.1365-2559.2011.03790.x.

10. Yasui S, Fujiwara K, Yonemitsu Y, Oda S, Nakano M, Yokosuka O. Clinicopathological features of severe and fulminant forms of autoimmune hepatitis. J Gastroenterol 2011;46:378-390.

Copyright $(2011$ by the American Association for the Study of Liver Diseases. View this article online at wileyonlinelibrary.com. DOI 10.1002/hep.24331

Potential conflict of interest: Nothing to report.

\section{Autoimmune Acute Liver Failure}

\section{To the Editor:}

We read with great interest the article entitled "Autoimmune Acute Liver Failure: Proposed Clinical and Histological Criteria" by Stravitz et al. ${ }^{1}$

Our reading of this article has given rise to several comments. It is necessary to be very cautious when one is ranking histological features first in the diagnosis and management of severe forms of autoimmune disease; during their study, Stravitz et al. ${ }^{1}$ examined liver biopsy samples from 72 of 204 patients (i.e., 35\% of the total cohort). However, the use of different liver biopsy techniques, such as transjugular liver biopsy, native liver biopsy, and postmortem biopsy, may have induced variations in the histological patterns. Centrilobular necrosis $(\mathrm{CN})$, which corresponds to massive hepatic necrosis type 1 in this study, is an important but infrequent histopathological pattern of autoimmune hepatitis; centrilobular necrosis with sparing of the portal tracts was present in $3.5 \%$ of the cases reported by Hofer et al. ${ }^{2}$ This particular pattern is of crucial importance because it may be indicative of an early stage of the disease. For the series described by Stravitz et al., it would be interesting to have a description of the phenotype and, more specifically, the prognosis of the patients with isolated centrilobular necrosis. The fact that the centrilobular zone is damaged during an early stage by the immune process is intriguing and suggests that specific autoantigens in this area could be presented to the immune system early during the course of liver disease. Clearly, the identification of these potential targets during an initial phase of the disease would be of considerable interest. In addition, it is unfortunate that the identification of a pattern typical of severe autoimmune hepatitis (AIH) is based only on this experience; in several reports, researchers have attempted to describe this entity, and experiences besides those of the US Acute Liver Failure Study Group should be cited. ${ }^{3-6}$ In particular, the characteristics of the patients may differ between the studies. In our cohort, 8 of 16 patients $(50 \%)$ suffered from grade $3 / 4$ encephalopathy, ${ }^{3}$ whereas 26 of 72 patients (39\%) in Stravitz et al.'s study did.
The most important and problematic issue in the management of severe autoimmune liver disease is corticosteroid therapy. Of course, if a response to corticosteroid therapy is an important argument in favor of an autoimmune process, it is important that any decision to administer this therapy be balanced against the high potential risk of sepsis; infections occurred in 5 of 12 patients $(42 \%)$ during steroid therapy in our study. ${ }^{3}$ If treatment failure seems to be predicted by changes in the Model for End-Stage Liver Disease-Sodium score and the UK Model for End-Stage Liver Disease score on day $7,{ }^{7}$ specific scores on entry must be defined for making decisions about the administration of steroid therapy.

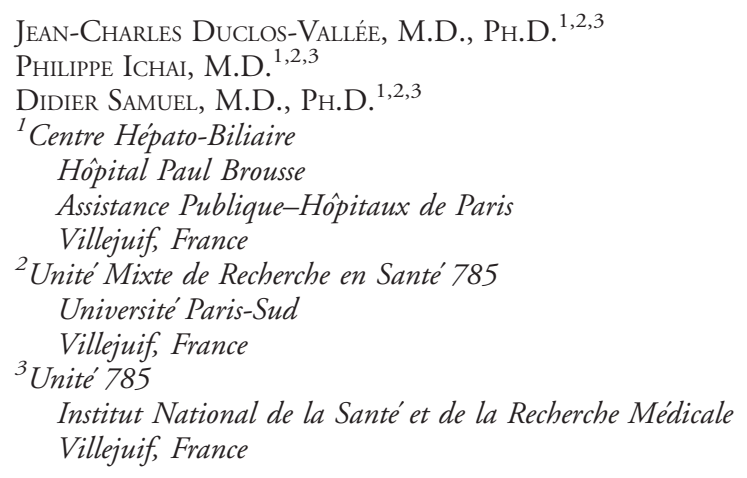

\section{References}

1. Stravitz RT, Lefkowitch JH, Fontana RJ, Gershwin ME, Leung PSC, Sterling RK, et al. Autoimmune acute liver failure: proposed clinical and histological criteria. Hepatology 2011;53:517-526.

2. Hofer H, Oesterreicher C, Wrba F, Ferenci, Penner E. Centrilobular necrosis in autoimmune hepatitis: a histological feature associated with acute clinical presentation. J Clin Pathol 2006;59:246-249. 
3. Ichai P, Duclos-Vallée JC, Guettier C, Ben Hamida S, Antonini T, Delvart V, et al. Usefulness of corticosteroids for the treatment of severe and fulminant forms of autoimmune hepatitis. Liver Transpl 2007;13:996-1003.

4. Herzog D, Rasquin-Weber AM, Debray D, Alvarez F. Subfulminant hepatic failure in autoimmune hepatitis type I: an unusual form of presentation. J Hepatol 1997;27:578-582.

5. Villamil AG, Casciato P, Eduardo M, Bustos D, Giunta D, Ciardullo $\mathrm{M}$, et al. Fulminant autoimmune hepatitis: clinical presentation, outcome and prognostic factors. Am J Transplant 2005;5(Suppl 11):278.

6. Czaja AJ. Corticosteroids or not in severe acute or fulminant autoimmune hepatitis: therapeutic brinksmanship and the point beyond salvation. Liver Transpl 2007;13:953-955.

7. Yeoman AD, Westbrook RH, Zen Y, Maninchedda P, Portmann BC, Devlin J, et al. Early predictors of corticosteroid treatment failure in icteric presentations of autoimmune hepatitis. HEPATOLOGY 2011;53:926-934.

Copyright $(2011$ by the American Association for the Study of Liver Diseases. View this article online at wileyonlinelibrary.com.

DOI 10.1002/hep.24337

Potential conflict of interest: Nothing to report.

\section{Reply:}

We appreciate the comments of Drs. Fujiwara and DuclosVallée regarding our article, "Autoimmune acute liver failure: proposed clinical and histological criteria." 1 Dr. Fujiwara reports that approximately $50 \%$ of their patient population with acute liver failure (ALF) of unclear etiology was ultimately diagnosed with autoimmune ALF (AI-ALF) on the basis of liver histology and clinical parameters, similar to findings in our series (58\%). The investigators advise caution in interpreting our work regarding the heterogeneity of histological findings in liver specimens from patients with ALF. Dr. Fujiwara presents data that demonstrate no difference between the time of onset of hepatitis to time of admission or liver biopsy between patients with autoimmune hepatitis presenting as acute-onset hepatitis, chronic hepatitis, or ALF, with a large degree of overlap, supporting the clinical heterogeneity of the disease.

Dr. Duclos-Vallée also raises concern about the fact that twothirds of our liver specimens were sections from explants, whereas the remainder were transjugular needle biopsies. The lack of uniform biopsy technique, they suggest, may have influenced our results by increasing the probability of finding specific features of autoimmunity in the larger specimens obtained from an explant. We did not, however, find statistically significant differences in the prevalence of the four features of autoimmunity between specimens obtained from explanted livers and those obtained by transjugular biopsy.

Dr. Duclos-Vallée also requested further correlation between patients with centrilobular necrosis and their clinical phenotype and outcomes. Patients with central perivenulitis were characterized by a longer jaundice-to-encephalopathy interval, and a poorer prognosis (higher incidence of liver transplantation). These attributes can be ascribed to a more subacute liver injury in patients with AI-ALF compared to those with other indeterminate etiologies. Perhaps due to small numbers (13 of 72 patients; $18 \%$ ), those patients with exclusive centrilobular necrosis were not clinically different than those without this feature.

Finally, Dr. Duclos-Vallée and colleagues raise concern about administering corticosteroids to patients with suspected AI-ALF, a major rationale for performing our study. We strongly agree with their contention that corticosteroid administration may introduce a significant risk of infection, and that no convincing evidence of efficacy exists. ${ }^{2}$ It should be noted, however, that no randomized, placebo-controlled studies have explored the efficacy of corticosteroids in patients with rigorously defined AI-ALF. In the absence of such information, we would reserve the administration of corticosteroids to patients with recent-onset AI-ALF and low-grade hepatic encephalopathy. Certainly, corticosteroids are unlikely to improve the transplant-free survival of a patient with AI-ALF late in the clinical course of the syndrome or with clinical attributes of poor outcome.

\author{
R. Todd STravitz, M.D. ${ }^{1}$ \\ JAY H. LEFKOWITCH, M.D. ${ }^{2}$ \\ ${ }^{1}$ Section of Hepatology, Virginia Commonwealth University \\ Richmond, VA \\ ${ }^{2}$ Department of Pathology, Columbia University, New York, NY
}

\section{References}

1. Stravitz RT, Lefkowitch JH, Fontana RJ, Gershwin ME, Leung PS, Sterling RK, et al. Autoimmune acute liver failure: proposed clinical and histological criteria. Hepatology 2011;53:517-526.

2. Ichai P, Duclos-Vallée JC, Guettier C, Hamida SB, Antonini T, Delvart $\mathrm{V}$ et al. Usefulness of corticosteroids for the treatment of severe and fulminant forms of autoimmune hepatitis. Liver Transpl 2007;13: 996-1003.

Copyright (C 2011 by the American Association for the Study of Liver Diseases. View this article online at wileyonlinelibrary.com.

DOI 10.1002/hep.24381

Potential conflict of interest: Nothing to report.

\section{Occult Hepatitis B Virus Infection and Hepatocellular Carcinoma Development in Patients with Chronic Hepatitis C}

\section{To the Editor:}

We read with interest the article by Lok et al. that assessed occult hepatitis B virus (HBV) infection in patients who are negative for hepatitis B surface antigen and who have advanced chronic hepatitis, from the Hepatitis Antiviral Long-Term Treatment against Cirrhosis (HALT-C) trial, who did or did not develop hepatocellular carcinoma (HCC). ${ }^{1}$ They conclude by affirming that occult HBV infection has no role in HCC development in U.S. patients with chronic hepatitis C.
After a detailed evaluation, we have several concerns regarding this conclusion. The authors themselves admit that their study has at least four main limitations. First, a limited number of patients with HCC were evaluated, and the diagnosis of cancer was simply presumed in some cases. In the HALT-C trial, the patients were randomly assigned to maintenance pegylated interferon or to no further treatment, and it would be relevant to know how the occult-positive patients were distributed according to treatment received and to definite or presumed HCC diagnosis. The second and third stated limitations concern the long storage duration and the very limited size of 
biopsy specimens examined: $2-3 \mathrm{~mm}$ of tissue obtained by percutaneous needle biopsy cannot provide reliable results. Theoretically, such a small piece of tissue may not actually be liver or could be fibrotic tissue. The fourth stated limitation concerns the lower number of HBV genomic regions tested as compared to previous studies that provided different results. It is also highly surprising that the $\mathrm{X}$ genomic region (the viral gene mainly involved in the direct oncogenic role of $\mathrm{HBV}$ ) was not searched in a study evaluating the association between HBV persistence and HCC development. Moreover, there is generic information about patient origins and, consequently, about the presumable infecting genotypes. Thus, the possibility that sensitivity and specificity of both amplification primers and probes was inadequate in a number of cases cannot be ruled out.

This study confirms previously reported (and not denied) data concerning the association between occult HBV and severe chronic hepatitis $\mathrm{C}$ in the United States. ${ }^{2}$ Considering the very low prevalence of HBV infection in the United States, this observation is interesting, ${ }^{3}$ and it would be very important to know the prevalence of occult HBV in U.S. patients infected with hepatitis $C$ virus, with minimal liver damage.

Altogether, we feel that there is still ample room for a role of occult HBV infection in the development of HCC in patients with chronic hepatitis, and that its categorical exclusion in the U.S. population is not sufficiently proven in the study by Lok et al.

Giovanni Raimondo, M.D. ${ }^{1}$

Teresa Pollicino, M.D. ${ }^{1}$

Massimo LeVrero, M.D. ${ }^{2}$

Antonio Craxì, M.D. ${ }^{3}$

${ }^{I}$ Clinical and Molecular Hepatology Unit, Department of Internal Medicine, University of Messina, Messina, Italy

${ }^{2}$ Department of Internal Medicine, La Sapienza University, Rome, Italy

${ }^{3}$ Gastroenterology Section, Dipartimento Biomedico di Medicina Interna e Specialistica (DIBIMIS), University of Palermo

Palermo, Italy

\section{References}

1. Lok AS, Everhart JE, Di Bisceglie AM, Kim H-Y, Hussain M, Morgan TR. Occult and previous hepatitis B virus infection are not associated with hepatocellular carcinoma in US patients with chronic hepatitis C. Hepatology 2011; 10.1002/hep.24257.

2. Shetty K, Hussain M, Nei L, Reddy KR, Lok AS. Prevalence and significance of occult hepatitis $\mathrm{B}$ in a liver transplant population with chronic hepatitis C. Liver Transpl 2008;14:534-540.

3. Shouval D. What is the clinical significance of the high prevalence of occult hepatitis B in US liver transplant patients with chronic hepatitis C? Liver Transpl 2008;14:418-419.

Copyright $\odot 2011$ by the American Association for the Study of Liver Diseases. View this article online at wileyonlinelibrary.com.

DOI 10.1002/hep.24379

Potential conflict of interest: Nothing to report.
Reply:

We appreciate the interest of Dr. Raimondo and colleagues in our article. ${ }^{1}$ Of the 91 patients with hepatocellular carcinoma (HCC) who were tested for hepatitis B core antibody (anti-HBc) in serum, 39 of $53(74 \%)$ patients negative for anti-HBc and 32 of 38 (84\%) patients positive for anti-HBc met criteria for definite HCC. Among the 28 patients with HCC who were tested for hepatitis B virus (HBV) DNA in the liver, 18 of 25 (72\%) HBV DNA-negative and two of three (67\%) HBV DNA-positive patients met criteria for definite HCC. We would like to point out that the diagnostic criteria for presumed HCC in the HALT-C Trial protocol-a new mass on ultrasound in conjunction with two other imaging studies showing a lesion with arterial enhancement, with or without washout or evidence of progression on follow-up-are very stringent and most, if not all, patients with presumed HCC would have met the current guidelines for diagnosis of HCC. Of the 25 patients with HCC who had undetectable HBV DNA in the liver, 10 were randomized to maintenance peginterferon and 14 to no treatment, whereas one developed HCC during the lead-in phase and was not randomized. All three patients with HCC who had detectable HBV DNA in the liver were in the control group. We acknowledge the limitations of the data based on testing of HBV DNA in the liver; however, serological data showed clearly that despite evidence of a high prevalence of prior $\mathrm{HBV}$ infection, there was absolutely no association with HCC. We note that failure to find an association of prior or occult $\mathrm{HBV}$ infection and HCC among patients with HCV-related cirrhosis is not confined to the United States. Even in Italy, one large study found no association between anti-HBc in serum and HCC or liverrelated deaths. $^{2}$

ANNA S. LoK, M.D. ${ }^{1}$

JAMEs E. Everhart, M.D. ${ }^{2}$

${ }^{1}$ Division of Gastroenterology, University of Michigan Medical Center Ann Arbor, MI

${ }^{2}$ National Institute of Diabetes and Digestive and Kidney Diseases National Institutes of Health, Bethesda, MD

\section{References}

1. Lok AS, Everhart JE, Di BisceglieAM, Kim HY, Hussain M, Morgan TR; the HALT-C Trial Group. Occult and previous hepatitis B virus infection are not associated with hepatocellular carcinoma in US patients with chronic hepatitis C. Hepatology 2011; doi: 10.1002/ hep. 24257.

2. Stroffolini R, Almasio P, Persico M, Bollani S, Benvegnù L, Di Costanzo G, et al. Lack of correlation between serum anti-HBcore detectability and hepatocellular carcinoma in patients with HCV-related cirrhosis. Am J Gastroenterol 2008;103:1966-1972.

Copyright $\odot 2011$ by the American Association for the Study of Liver Diseases. View this article online at wileyonlinelibrary.com. DOI 10.1002/hep.24410

Potential conflict of interest: Nothing to report. 


\section{Association Between Human Leukocyte Antigen DP Gene Polymorphisms and Chronic Hepatitis B in a Chinese Population}

\section{To the Editor:}

We read with great interest the article by Guo et al., ${ }^{1}$ which suggested that 11 polymorphisms of human leukocyte antigen DP genes were significantly associated with chronic hepatitis $B$ in a Chinese population. These significant associations were first reported by a genome-wide association study in Japanese and Thai populations. ${ }^{2}$ Since then, besides the study by Guo et al, ${ }^{1}$ two studies further confirmed the significant associations. ${ }^{3,4}$ These studies are very important, because the findings would help us more deeply understand the genetic mechanism of chronic hepatitis B. However, after carefully inspecting the article by Guo et al., ${ }^{1}$ we noted four issues that should be considered.

First, the authors stated that the Bonferroni correction was the current $P$ value times 4 . In my opinion, it is not true. On the basis of data in Table 2 , the $P$ value should be multiplied by 8 [( 2 haplotype blocks +2 variants (rs3135021 + rs11752643)) $\times 2$ group comparisons]; in Table 3, the multiplication should be by 12 [( $(2$ haplotype blocks +1 variant $($ rs3135021) $) \times 2$ genotype comparisons for each variant $\times 2$ group comparisons)]. Therefore, the $P$ value for statistical significance in Table 2 should be $0.05 / 8=$ 0.00625 and that in Table 3 should be $0.05 / 12=0.00417$. On the basis of the new $P$ values, the association between rs 2395309 and chronic hepatitis B is not statistically significant after Bonferroni correction (Table 3).

Second, the authors did not provide the statistical powers of their studied sample for each variant. Therefore, I am not certain whether the statistically significant results are the true ones or are due to chance. It is always better to present the statistical powers.

Third, it is more proper to move the notes of Armitage's trend test in Table 2 to the notes in Table 3, because the three genotypes for each variant in Table 3, rather than those in Table 2 , showed the trends.

Fourth, the order in which the three genotypes are listed under each SNP variant, namely rs9277341, rs9277535, rs3117222, and rs9380343, is not uniform in Table 2 and Table 3, and this would confuse the readers. Therefore, we suggest that the authors should keep odds ratios with $95 \%$ confidence intervals in the same direction in order to present their results more clearly.

\section{Chibo Liu, M.B. \\ Department of Clinical Laboratory Taizhou Municipal Hospital Taizhou, China}

\section{References}

1. Guo X, Zhang Y, Li J, Ma J, Wei Z, Tan W, et al. Strong influence of human leukocyte antigen ( $H L A)-D P$ gene variants on development of persistent chronic hepatitis B virus carriers in the Han Chinese population. Hepatology 2011;53:422-428.

2. Kamatani Y, Wattanapokayakit S, Ochi H, Kawaguchi T, Takahashi A, Hosono N, et al. A genome-wide association study identifies variants in the HLA-DP locus associated with chronic hepatitis B in Asians. Nat Genet 2009;41:591-595.

3. An P, Winkler C, Guan L, O'Brien SJ, Zeng Z; the HBV Study Consortium. A common HLA-DPA1 variant is a major determinant of hepatitis B virus clearance in Han Chinese. J Infect Dis 2011;203:943-947.

4. Wang L, Wu XP, Zhang W, Zhu DH, Wang Y, Li YP, et al. Evaluation of genetic susceptibility loci for chronic hepatitis B in Chinese: two independent case-control studies. PLoS One 2011;6:e17608.

\author{
Copyright $\bigcirc 2011$ by the American Association for the Study of Liver Diseases. \\ View this article online at wileyonlinelibrary.com. \\ DOI 10.1002/hep.24411 \\ Potential conflict of interest: Nothing to report.
}

\section{Reply:}

We do appreciate that there are legitimate differences of opinion with respect to correction for multiple tests as the letter by Dr. Liu aptly illustrates. Our study ${ }^{1}$ was designed to replicate a previously published genome-wide association study. ${ }^{2}$ One opinion is, in this case, that a correction for multiple comparisons is unnecessary. In our study, however, we still address it. We state that a Bonferroni test may be too conservative given the nonindependence of adjacent single-nucleotide polymorphisms (SNPs) strongly associated by linkage disequilibrium ${ }^{3}$ (see Johnson et al. ${ }^{3}$ for our detailed discussion of linkage disequilibrium statistics on genome-wide association studies). Nonetheless, even if we concede to the more stringent statistical correction offered by Dr. Liu in his comment $(0.05 / 8=0.00625$ for table 2 and $0.05 / 12$ $=0.00417$ for table 3 ), nearly all the associations for SNP alleles (table 2) or genotypes (table 3) still achieve statistical significance after correction. Only rs3135021 fails significance. We feel that our data are robust and statistically strong in support of the associations of the SNP alleles, genotypes, and haplotypes illustrated in table 2 to table 4 and figure 1 .

The statistical power of our study for the additive model is $89 \%$ $100 \%$, based on case number, control number, disease prevalence (0.08), significance level (0.05), disease allele frequency (0.3340.797 ), and genotype relative risk (1.5). Also, the data reported in table 2 were actually from Armitage's trend test (computed with SAS Genetics software), which is most useful when there is an additive allele effect on the disease susceptibility.

As for the direction (i.e., the polarity of odds ratios [ORs]), this format is also a matter of taste. We chose to base our tables on the risk allele (protective allele as a reference) with $\mathrm{OR}<1.0$, which we state. For example, for rs2395309, the OR should be $1 / 0.71=1.41$, and $95 \%$ confidence interval should be 1.16-1.69 (formula is $1 / 0.86=1.16,1 / 0.59=1.69$ ) for risk allele G. We realize that use of the term "risk allele" might be confusing, because some alleles protect whereas others are susceptible, as indicated by the OR. For this confusion, we stand corrected. We apologize for the confusion, but when one examines the OR, it seemed clearly stated to us.

For table 3, we list the reference group $(\mathrm{OR}=1.0)$, and the most common genotype was used as a reference for each SNP.

XiUchan Guo, M.D. ${ }^{1}$

RANDALl C. JOHNSON, MHS ${ }^{2}$

STEPHEN J. O’BRIEN, Ph.D. ${ }^{2}$

${ }^{1}$ State Key Laboratory for Infectious Diseases Prevention and Control Institute for Viral Disease Control and Prevention

Chinese Center for Disease Control and Prevention Beijing, China

${ }^{2}$ Laboratory of Genomic Diversity National Cancer Institute-Frederick

Frederick, $M D$ 


\section{References}

1. Guo X, Zhang Y, Li J, Ma J, Wei Z, Tan W, et al. Strong influence of human leukocyte antigen (HLA)-DP gene variants on development of persistent chronic hepatitis B virus carriers in the Han Chinese population. Hepatology 2011;53:422-428.

2. Kamatani Y, Wattanapokayakit S, Ochi H, Kawaguchi T, Takahashi A, Hosono N, et al. A genome-wide association study identifies variants in the HLA-DP locus associated with chronic hepatitis B in Asians. Nat Genet 2009;41:591-595.
3. Johnson RC, Nelson GW, Troyer JL, Lautenberger JA, Kessing BD, Winkler CA, et al. Accounting for multiple comparisons in a genome-wide association study (GWAS). BMC Genomics 2010;11: 724.

Copyright $@ 2011$ by the American Association for the Study of Liver Diseases. View this article online at wileyonlinelibrary.com. DOI 10.1002/hep.24448

Potential conflict of interest: Nothing to report.

\section{Neutralization of Lipopolysaccharide Effects in Liver Diseases, the Quest for the Holy Grail}

\section{To the Editor:}

We read with great interest the article in Hepatology by Nolan on the role of lipopolysaccharide (LPS) in liver injury. ${ }^{1}$ This review, written by a pioneer of this approach, details the main studies that progressively established gut-derived LPS as a key cofactor in acute and chronic liver disease in the last half-century and more recent studies that tried to prevent LPS-induced damages by reducing or by neutralizing plasma LPS or proinflammatory cytokines. However, we think some important recent studies should have been discussed in this review.

Among the studies exploring possibilities to neutralize LPS, those which assessed the effects high-density lipoprotein (HDL) have not been mentioned. ${ }^{2-4}$ HDL particles are multifunctional lipoprotein complexes that transport lipids and have several anti-inflammatory properties. In cirrhosis, HDL plasma concentrations are decreased and could impair the host's ability to neutralize LPS. ${ }^{3}$ In cirrhotic rats with ascites, two recent studies have shown that HDL administration reduced the effects of LPS on tumor necrosis factor- $\alpha$ production $^{2,4}$ and systemic hemodynamics, restoring liver endothelial nitric oxide synthase activity and decreasing portal pressure. ${ }^{2}$ These studies suggest that the excessive proinflammatory response to LPS in cirrhosis may be attributable, at least in part, to reduced LPS neutralization by HDL. Incubation of whole blood with reconstituted HDL prevents LPS-induced tumor necrosis factor- $\alpha$ and interleukin- 6 overproduction by monocytes of patients with cirrhosis. $^{3}$ Therefore, we believe that restoring HDL content in patients with cirrhosis may be a research avenue to follow in the future.

We are conscious that mentioning all the studies related to this crucial subject is very difficult, but we think that the studies we report here are worth being cited in such a review.
Arnaud Galbois, M.D. ${ }^{1,2,3}$

Dominique Thabut, M.D., Ph.D. 2,3,4

Richard Moreau, M.D., Ph.D. ${ }^{5,6}$

Didier Lebrec, M.D., Ph.D. ${ }^{5,6}$

${ }^{1}$ Université Pierre et Marie Curie Université de Paris 6, Unite' Mixte de Recherche_S 938, CdR Saint-Antoine, Paris, France

${ }^{2}$ Institut National de la Santé et de la Recherche Médicale (INSERM), UMR_S 938, CdR Saint-Antoine, Paris, France

${ }^{3}$ Assistance Publique-Hôpitaux de Paris (AP-HP), Hôpital

Saint-Antoine, Service de Réanimation Médicale, Paris, France

${ }^{4} A P-H P$, Hôpital la Pitié-Salpêtrière, Service d'Hépato-gastroentérologie, Paris, France

'INSERM, Unite' 773, Centre de Recherche Biomédicale BichatBeaujon CRB3, Paris, France

${ }^{6}$ AP-HP, Hôpital Beaujon, Service d'Hépatologie, Clichy, France

\section{References}

1. Nolan JP. The role of intestinal endotoxin in liver injury: a long and evolving history. Hepatology 2010;52:1829-1835.

2. Thabut D, Tazi KA, Bonnefont-Rousselot D, Aller M, Farges O, Guimont $\mathrm{MC}$, et al. High-density lipoprotein administration attenuates liver proinflammatory response, restores liver endothelial nitric oxide synthase activity, and lowers portal pressure in cirrhotic rats. HePATOLOGY 2007;46:1893-1906.

3. Galbois A, Thabut D, Tazi KA, Rudler M, Mohammadi MS, Bonnefont-Rousselot D, et al. Ex vivo effects of high-density lipoprotein exposure on the lipopolysaccharide-induced inflammatory response in patients with severe cirrhosis. Hepatology 2009;49:175-184.

4. Ramirez MJ, Ibanez A, Navasa M, Casals E, Morales-Ruiz M, Jimenez $\mathrm{W}$, et al. High-density lipoproteins reduce the effect of endotoxin on cytokine production and systemic hemodynamics in cirrhotic rats with ascites. J Hepatol 2004;40:424-430.

Copyright $\odot 2011$ by the American Association for the Study of Liver Diseases. View this article online at wileyonlinelibrary.com. DOI 10.1002/hep.24186

Potential conflict of interest: Nothing to report.

\section{Alpha-Fetoprotein in Hepatocellular Carcinoma Surveillance: Wake Not the Dead}

\section{To the Editor:}

We read with interest the letter by Marrero and El-Serag that calls for the inclusion of alpha-fetoprotein (AFP) in the American Association for the Study of Liver Diseases (AASLD) updated guidelines for the management of hepatocellular carcinoma (HCC). ${ }^{1,2}$ However, we disagree with their conclusions and feel that the AASLD recommendation to perform HCC surveillance with ultrasonography (US) alone is supported by solid evidence. ${ }^{1,2}$

The evidence supporting surveillance programs for HCC with liver US with or without AFP testing stems from the results of a randomized controlled trial and from cohort studies showing that surveillance improves both detection rate of early HCCs and patient survival. $^{3-5}$ However, it is clear that the authors of the AASLD 
guidelines took into account the numerous limitations of AFP testing and therefore it is no surprise that they did not include this serological marker in their HCC surveillance recommendations. ${ }^{2}$ In fact, although we may agree with Marrero and El-Serag that the Hepatitis C Antiviral Long-Term Treatment Against Cirrhosis (HALT-C) trial is a suboptimal setting to assess the role of AFP for the early detection of HCC, this study had the precious gifts of providing prospectively collected data and to include a large population of patients who were mainly at risk of developing HCC. ${ }^{6}$ Furthermore, data were available both at HCC diagnosis and 1 year before, thus being as close as possible to everyday clinical practice and therefore providing the best evidence currently available. ${ }^{2,6}$ In this study, the sensitivity of AFP at a cutoff of $20 \mathrm{ng} / \mathrm{mL}$ was low (i.e., 61\%) at the time of HCC diagnosis, yet at $22 \%$ it was unacceptably low 12 months before, when HCC was likely present in the majority of patients. ${ }^{6}$ These results are strikingly similar to those obtained in a case-control study carried out in a completely different population, where a $20 \mathrm{ng} / \mathrm{mL}$ AFP cutoff showed $60 \%$ sensitivity for the diagnosis of HCC, ${ }^{7}$ although sensitivity was unacceptably low (i.e., approximately 50\%) for single nodules and/or lesions smaller than $3 \mathrm{~cm}$.

We feel that the extensors of the updated AASLD guidelines did not ignore the "highest level of evidence for the efficacy of US combined with AFP in research studies" ${ }^{2}$ as affirmed by Marrero and El-Serag, ${ }^{1}$ but evaluated both efficacy and cost-effectiveness. Indeed, the combination of AFP and US leads to a mere $6 \%-8 \%$ increase in sensitivity for the detection of early HCC as compared to US alone, with a doubling in the rate of false-positives and at an unbearable increase (by 84\%) in surveillance-related costs. ${ }^{9,10}$ Therefore, AFP provides no additional benefit to US, as recently concluded even in the meta-analysis by the Marrero group, ${ }^{10}$ with a significant worsening of the cost-effectiveness of surveillance.' To conclude, we feel that the use of AFP as a surveillance test for HCC should be regarded as a memory, and any effort to increase the awareness and application of the currently proposed surveillance guidelines among physicians in clinical practice should be embraced.

Edoardo G. Giannini, M.D., Ph.D. ${ }^{1}$

Fabio Farinati, M.D. ${ }^{2}$

Franco Trevisani, M.D. ${ }^{3}$

${ }^{1}$ Department of Internal Medicine, Gastroenterology Unit University of Genova, Genova, Italy

${ }^{2}$ Department of Surgical and Gastroenterological Science, Gastroenterology Unit, University of Padova, Padova, Italy

${ }^{3}$ Department of Clinical Medicine, Unità di Semeiotica Medica

Alma Mater Studiorum-University of Bologna, Bologna, Italy

\section{References}

1. Marrero JA, El-Serag HB. Alpha-fetoprotein should be included in the hepatocellular carcinoma surveillance guidelines of the American Association for the Study of Liver Diseases. Hepatology 2010; doi:10.1002/ hep. 24033

2. Bruix J, Sherman M. Management of hepatocellular carcinoma: an update. http://www.aasld.org/practiceguidelines/Documents/Bookmarked\%20Practice \%20Guidelines/HCCUpdate2010.pdf. Accessed January 19, 2011.

3. Yuen MF, Cheng CC, Lauder IJ, Lam SK, Ooi CG, Lai CL. Early detection of hepatocellular carcinoma increases the chance of treatment: Hong Kong experience. Hepatology 2000;31:330-335.

4. Zhang BH, Yang BH, Tang ZY. Randomized controlled trial of screening for hepatocellular carcinoma. J Cancer Res Clin Oncol 2004;130: 417-422.

5. Santi V, Trevisani F, Gramenzi A, Grignaschi A, Mirici-Cappa F, Del Poggio P, et al. Semiannual surveillance is superior to annual surveillance for the detection of early hepatocellular carcinoma and patient survival. J Hepatol 2010;53:291-297.

6. Lok AS, Sterling RK, Everhart JE, Wright EC, Hoefs JC, Di Bisceglie $\mathrm{AM}$, et al. Des-gamma-carboxy prothrombin and alpha-fetoprotein for the early detection of hepatocellular carcinoma. Gastroenterology 2010; 138:493-502.

7. Trevisani F, D’Intino PE, Morselli-Labate AM, Mazzella G, Accogli E, Caraceni P, et al. Serum alpha-fetoprotein for the diagnosis of hepatocellular carcinoma in patients with chronic liver disease: influence of HBsAg and anti-HCV status. J Hepatol 2001;34:570-575.

8. Farinati F, Marino D, De Giorgio M, Baldan A, Cantarini M, Cursaro $C$, et al. Diagnostic and prognostic role of $\alpha$-fetoprotein in hepatocellular carcinoma: both or neither? Am J Gastroenterol 2006; 101:524-532.

9. Zhang B, Yang B. Combined alpha fetoprotein testing and ultrasonography as a screening test for primary liver cancer. J Med Screen 1999; 6:108-110.

10. Singal A, Volk ML, Waljee A, Salgia R, Higgins P, Rogers MA, et al. Meta-analysis: surveillance with ultrasound for early-stage hepatocellular carcinoma in patients with cirrhosis. Aliment Pharmacol Ther 2009;30: $37-47$.

Copyright $\odot 2011$ by the American Association for the Study of Liver Diseases. View this article online at wileyonlinelibrary.com. DOI 10.1002/hep.24196

Potential conflict of interest: Nothing to report.

\section{Treatment Implication from the Potential Association Between Nonalcoholic Fatty Liver Disease and Cardiovascular Disease}

\section{To the Editor:}

In recent years, the potential association between nonalcoholic fatty liver disease (NAFLD) and cardiovascular disease (CVD) has attracted much interest, ${ }^{1}$ generating discussion that NAFLD patients should perhaps be treated not only for their liver disorder but also owing to their associated cardiovascular risk factors. However, it seems that at present we cannot draw a definitive conclusion on the association between NAFLD and CVD. I read with great interest the article by Ghouri et al., ${ }^{2}$ who reviewed data from recent prospective studies and concluded that a diagnosis of NAFLD is insufficient to consider patients as being at high risk for CVD. Nevertheless, it is interesting to note that Targher et al. ${ }^{3}$ recently reviewed the rapidly growing body of clinical evidence supporting a strong link between NAFLD and the CVD risk.
Therefore, additional effort is encouraged to shed light on the link between the two disorders.

I do not intend to judge the association between NAFLD and CVD; however, I sincerely hope the current debatable status will not hamper the research community to optimize the treatment strategy. Before drawing a definitive conclusion on the association between the two disorders, I submit that the NAFLD treatment strategy, which also possesses the potential to prevent/reduce the associated risk of CVD, may serve as a good approach for NAFLD patients. The advantage of this strategy is that if no or only a weak association between NAFLD and CVD is found, the approach will not bring additional burden to the patients. There have been numerous clinical trials of various treatment modalities for NAFLD as comprehensively reviewed by Lam and Younossi, ${ }^{4}$ including weight loss agents, insulin-sensitizing agents, lipid- 
lowering agents, antioxidants, probiotics, and other novel compounds. In addition, Satapathy and Sanyal ${ }^{5}$ recently discussed the status of current and emerging treatment strategies for nonalcoholic steatohepatitis patients and highlighted the great potential of antioxidant therapy. Because the treatment strategies for NAFLD and CVD are similar, it is promising to consider that one of the abovementioned treatment modalities for NAFLD could also be applied for associated risk of CVD.

LiAng SHEN, Ph.D.

Shandong Provincial Research

Center for Bioinformatic Engineering and Technique

Shandong University of Technology, Zibo, P. R. China

\section{References}

1. Targher G, Marra F, Marchesini G. Increased risk of cardiovascular disease in non-alcoholic fatty liver disease: causal effect or epiphenomenon? Diabetologia 2008;51:1947-1953.
2. Ghouri N, Preiss D, Sattar N. Liver enzymes, nonalcoholic fatty liver disease, and incident cardiovascular disease: a narrative review and clinical perspective of prospective data. Hepatology 2010;52: 1156-1161.

3. Targher G, Day CP, Bonora E. Risk of cardiovascular disease in patients with nonalcoholic fatty liver disease. N Engl J Med 2010; 363:1341-1350.

4. Lam B, Younossi ZM. Treatment options for nonalcoholic fatty liver disease. Therap Adv Gastroenterol 2010;3:121-137.

5. Satapathy SK, Sanyal AJ. Novel treatment modalities for nonalcoholic steatohepatitis. Trends Endocrinol Metab 2010;21:668675 .

Copyright $@ 2011$ by the American Association for the Study of Liver Diseases. View this article online at wileyonlinelibrary.com. DOI 10.1002/hep.24213

Potential conflict of interest: Nothing to report.

\section{Are There More Factors Other than Hepatitis B Virus DNA Level and A1762T/G1764A Mutation in Liver Tissue that Also Independently Predict Postoperative Survival in Hepatocellular Carcinoma?}

\section{To the Editor:}

We read with great interest the study by Yeh et al. ${ }^{1}$ on hepatitis B virus (HBV)-DNA level and basal core promoter A1762T/G1764A mutation in liver tissue independently predicting postoperative survival in hepatocellular carcinoma (HCC). According to the article, the amount of HBV-DNA in liver tissue and the presence of the basal core promoter mutation were two independent predictors for postoperative survival in HCC. The authors also found that a shortstretch pre-S deletion located between codons 107 and 141 was associated with a poorer postoperative prognosis. This study can be hailed as an original contribution in terms of predicting postoperative survival in HCC; however, we have some concerns about it.

First, as is well known, evidence suggests that $\mathrm{HBV}$ genetic mutations contribute to the risk of HCC. Recent studies have shown that HBV genotype- or subgenotype-specific mutations, including $\mathrm{C} 1653 \mathrm{~T}$ in the EnhII region, T1753V, and the double mutant A1762T/G1764A in the BCP region, are independent risk factors for HCC. ${ }^{2}$ Another study has indicated that pre-S deletions, I68T in surface gene, T1762/A1764, and A1899 are independent risk factors for $\mathrm{HCC}^{3}$ A recent meta-analysis revealed that the HBV pre-S mutations C1653T, T1753V, and A1762T/ G1764A are associated with an increased risk of HCC. These mutations alone and in combination may be predictive of hepatocarcinogenesis. ${ }^{4}$ We wonder whether the other gene mutations correlated with $\mathrm{HCC}$ in $\mathrm{HBV}$ other than the basal core promoter A1762T/G1764A mutation (e.g., C1653T, T1753V, A1899) can independently predict postoperative survival in HCC.

Second, it has not been determined whether hepatitis B e antigen $(\mathrm{HBeAg})$ is associated with postresection survival in HCC. According to Sun et al., ${ }^{5} \mathrm{HBeAg}$ was associated with a higher risk of early recurrence and poorer survival in patients after curative resection of small HCC. However, Chen et al. ${ }^{3}$ indicated that $\mathrm{HBeAg}$ positivity is not a negative factor for resection in HCC patients and has no significant influence on postresection survival. Therefore, we wonder whether $\mathrm{HBeAg}$ was associated with postresection survival in HCC in the study by Yeh et al. Given that the serum samples used in the study had been stored in the serum bank, we think that the detection of HBeAg in both groups is convenient and has great significance.

Finally, a study by Tomimaru et al. ${ }^{6}$ showed that histological assessment of the degree of fibrosis in noncancerous tissue is a unique prognostic factor for primary HCC without hepatitis B or $\mathrm{C}$ viral infection. If this is the case, then is histological assessment of the degree of fibrosis in noncancerous tissue one of the prognostic factors for HBV-related HCC as well?

\author{
YONG-NING XIN \\ ZHONG-HUA LiN \\ SHI-YING XUAN \\ Qingdao Municipal Hospital, Qingdao \\ Shandong Province, China
}

\section{References}

1. Yeh CT, So M, Ng J, Yang HW, Chang ML, Lai MW, et al. Hepatitis B virus-DNA level and basal core promoter A1762T/G1764A mutation in liver tissue independently predict postoperative survival in hepatocellular carcinoma. Hepatology 2010;52:1922-1933.

2. Sung JJ, Tsui SK, Tse CH, Ng EY, Leung KS, Lee KH, et al. Genotype-specific genomic markers associated with primary hepatomas, based on complete genomic sequencing of hepatitis B virus. J Virol 2008;82:3604-3611.

3. Chen $\mathrm{CH}$, Changchien $\mathrm{CS}$, Lee $\mathrm{CM}$, Hung $\mathrm{CH}, \mathrm{Hu} \mathrm{TH}$, Wang JH, et al. Combined mutations in pre-s/surface and core promoter/precore regions of hepatitis B virus increase the risk of hepatocellular carcinoma: a case-control study. J Infect Dis 2008;198:1634-1642.

4. Liu S, Zhang H, Gu C, Yin J, He Y, Xie J, et al. Associations between hepatitis $\mathrm{B}$ virus mutations and the risk of hepatocellular carcinoma: a meta-analysis. J Natl Cancer Inst 2009;101:1066-1082.

5. Sun HC, Zhang W, Qin LX, Zhang BH, Ye QH, Wang L, et al. Positive serum hepatitis $\mathrm{B}$ e antigen is associated with higher risk of early recurrence and poorer survival in patients after curative resection of hepatitis Brelated hepatocellular carcinoma. J Hepatol 2007;47:684-690.

6. Tomimaru Y, Sasaki Y, Yamada T, Eguchi H, Ohigashi H, Ishikawa O, et al. Fibrosis in non-cancerous tissue is the unique prognostic factor for primary hepatocellular carcinoma without hepatitis $\mathrm{B}$ or $\mathrm{C}$ viral infection. World J Surg 2006;30:1729-1735.

Copyright $(2011$ by the American Association for the Study of Liver Diseases. View this article online at wileyonlinelibrary.com.

DOI 10.1002/hep.24211

Potential conflict of interest: Nothing to report. 


\section{Risk Factors for Infection in Chronic Hepatitis C: A High Prevalence of Sexual Exposure Among Human Immunodeficiency Virus-Coinfected Women}

\section{To the Editor:}

We have read with great interest Tohme and Holmberg's review ${ }^{1}$ in Hepatology on the sexual transmission of hepatitis $\mathrm{C}$ virus (HCV). They distinguished between heterosexual and homosexual contacts and also between monoinfected and human immunodeficiency virus (HIV)-coinfected patients, and they affirmed the recently reported increasing incidence of HCV infection among HIV-positive men who have sex with men.

We analyzed the risk factors for infection in a series of 886 consecutive patients [median age $=40$ years, interquartile range $=33$ 53 years, 521 males $(58.8 \%)$ ] with chronic hepatitis $\mathrm{C}$ who were followed up in our liver unit; 198 of these patients (22.3\%) were HIV-coinfected. A risk-factor questionnaire was prospectively collected by the members of the unit (i.e., us). We considered the risk factor for HCV infection to be sexual exposure (SEXEXP) only in patients who fulfilled the following criteria: (1) a negative history for intravenous drug use (IDU), inhalatory drug use (INHDU), or blood transfusions (BTs) before 1994 and (b) a sexual partner who was recognized to be anti-HCV-positive.

The main risk factors in the whole group of patients were IDU (32.5\%), BTs (19.4\%), INHDU (8.9\%), and SEXEXP (8.6\%). In $20.2 \%$ of the patients, no risk factors were identified. However, we found significant differences in the risk factors between males and females [the main ones were IDU (47.4\%) and BTs (30.5\%), respectively; SEXEXP was considered to be the probable risk factor in only $1.7 \%$ of men but in $18.3 \%$ of women $(P=0.0000)$ ]. There were also significant differences between monoinfected HCV patients ( $\mathrm{n}=687$, age $=46 \pm 14$ years $)$ and HIV-coinfected patients ( $\mathrm{n}=198$, age $=35 \pm 6$ years). In the first group, $24.4 \%$ had a history of BTs, $23.5 \%$ had a history of IDU, and $9.1 \%$ had a history of INHDU; in the second group, a history of IDU was predominant $(62.1 \%)$, and it was followed by SEXEXP (20.5\%).

In our opinion, the more interesting finding is the relationship between females $(n=365)$ and SEXEXP as the probable route of
HCV transmission. The definition of SEXEXP was fulfilled by $10 \%$ of monoinfected women $(n=292$, age $=51 \pm 15$ years $)$, whereas in the group of HIV-coinfected women $(\mathrm{n}=73$, age $=$ $35 \pm 7$ years), the percentage was more impressive: $49 \%$. Although this subgroup of coinfected women is small, it seems to us that this finding is worthy of being reported. The sexual partners of these women are also our patients; most have the same $\mathrm{HCV}$ genotype as their wives, and they usually have a history of IDU. Thus, we have to rely on clinical histories to exclude this background in women. In conclusion, we have found SEXEXP to be a very prevalent risk factor for $\mathrm{HCV}$ infection in HIV-coinfected women. The transmission of HCV might be secondary to high viremia levels in their partners in the period before antiretroviral treatment. This result should be further addressed in a larger population.

\author{
Eduardo Fassio, M.D. \\ Graciela Landeira, M.D. \\ Cristina Longo, M.D. \\ Nora Domínguez, M.D. \\ Estela Alvarez, M.D. \\ Gisela Gualano, M.D. \\ Hospital Nacional Profesor Alejandro Posadas \\ Buenos Aires, Argentina
}

\section{Reference}

1. Tohme RA, Holmberg SD. Is sexual contact a major mode of hepatitis C virus transmission? Hepatology 2010;52:1497-1505.

Copyright $(2011$ by the American Association for the Study of Liver Diseases. View this article online at wileyonlinelibrary.com. DOI 10.1002/hep.24224

Potential conflict of interest: Nothing to report. 